New Zealand journal of industrial relations, 1987, 12, 61-70

\title{
Union policies and the structure of part-time employment: the case of registered nursing
}

\author{
Sylvia Dixon*
}

This paper considers the impact of the New Zealand Nurses Association and the Public Service Association upon the development of part-time employment patterns in public hospital-based registered nursing. It argues that an understanding of the policies and negotiating strategies of unions and professional associations is required for a full explanation of part-time employment's uneven industrial and occupational distribution.

\section{Introduction}

Part-time employees are an expanding component of the labour force in a large number of western industrial nations. In New Zealand, the proportion of employees in non-agricultural industries who were employed for less than 30 hours a week rose from roughly 1 in 40 (2.4 percent) in 1947 to 1 in 6 (16.8 percent) in 1986 (Quarterly employment survey). Typically however, the growth of part-time employment in OECD nations has not been evenly distributed across the labour force. In New Zealand, the growth has been heavily concentrated in the service and retail industries, with relatively little expansion over the last decade in manufacturing, construction, transport and communications, or in the primary industries. Part-time job growth has also been concentrated in the service, clerical, and sales occupational groups, with far fewer part-time jobs being created in production and transportation, administrative and managerial, or primary sector occupations (Clark, 1986; Dixon, 1985; Shipley, 1982).

Social scientists have offered a variety of explanations for part-time employment's uneven development. Firstly, the importance of labour shortages in prompting employers to introduce or expand part-time jobs has frequently been emphasised (Hallaire, 1968, p. 40; Nollen et al., 1978, p. 29; Robinson, 1979, p. 310). Part-time labour has been used as a substitute for full-time labour when it is in short supply. At an occupational level, staff recruitment and retention problems appear to have been particularly influential in bringing about a post-war expansion of part-time jobs in a number of the traditionally female professions, such as nursing, teaching and social work. Studies of staffing trends in these occupations in Britain and in other western nations, provide evidence that employers have offered part-time jobs in order to attract already trained and experienced women back into employment when their skills were in short supply (Aiken, 1984, p. 20; Bennett, 1962, p. 347; Hall and Hall, 1980, p. 95; Kelsall, 1980, p. 187; MacGuire, 1980, p. 147; Thomas and Deaton, 1977, p. 120).

Secondly, the growth of part-time employment in particular industries and occupations has been explained in terms of a management need for flexibility in the development and scheduling of labour (OECD, 1983, p. 46; Syrett, 1983, p. 10). In workplaces where extended hours of service are required or where there are predictable peaks and fluctuations in workloads, part-time employment permits staffing levels to be more closely matched to the changing level of work activity, and enables staff coverage to be extended beyond the standard 40-hour, 5-day week without the need for overtime or shiftwork. Daily and weekly fluctuations in business activity help to explain why certain industries have always had a higher proportion

Advisory Officer, Department of Labour. The views expressed in this article are those of the author, not those of the Department of Labour. The author wishes to thank Geoff Fougere. Derek Best. Denis Asher and the journal's anonymous referees for their helpful comments on earlier drafts of this paper. Any errors are the responsibility of the author. 
of part-time workers than others, as in the case of services and retail trade (White, 1983, p. 40). Empirical studies of the management of part-time staffing decision have also provided strong support for the notion that the desire for labour scheduling flexibility is often a key motivating factor in the employer's decision to expand part-time employment (Beechey and Perkins, 1985, p. 254; Bosworth and Dawkins, 1982, p. 34; Nollen et al., 1978, p. 29, Robinson and Wallace, 1984, p. 29).

Thirdly, it has been argued that the uneven utilisation of part-time labour across the workforce is directly related to patterns of occupational segregation by gender (Beechey and Perkins, 1985, p. 255; Humphries, 1983, p. 14; White, 1983, p. 45). The labour force is highly segregated by sex and it is largely women, the young and the old rather than mature-aged males who seek part-time hours. Where the full-time labour force is female, managers use part-time employment to extend hours of work or to adjust staffing to peaks and troughs in work activity. Where the full-time labour force is male, by contrast, managers opt for shiftwork systems or overtime to attain the necessary scheduling flexibility. Thus the patterns of part-time working are closely linked to the existence of occupational segregation by sex (Beechey and Perkins, 1985 , p. 261).

Relatively little attention has been paid so far in the literature on part-time employment to the influence of trade unions and professional associations on part-time employment's industrial and occupational structure. A number of writers have noted that trade union opposition is potentially an important barrier to the growth of part-time employment, and have identified some of the general reasons for this opposition (Canadian Commission of Inquiry, 1983, p 9; Nollen et al.. 1978, p 128; White, 1983, pp 53-56). For example, unions in Canada and the United States have objected to part-time employment because of the potential they believe it offers for labour cost savings through the reduction of employment benefits; because of the special problems that part-time workers can present for collective organisation: and because of the threat they believe part-time job growth poses for the job security and stability of the workforce (Canadian Commission of Inquiry, 1983, p. 9; Nollen et al., 1978, pp. 128-31). As yet however, few writers have gone on to identify the reasons for union opposition to part-time employment in particular industries or occupations, or to explore the implications of these attitudes and policies for the availability and labour market distribution of part-time jobs. The actions taken by professional associations to regulate part-time job opportunities within their sphere of employment have also been overlooked.

This paper provides a case study of the impact of trade union organisation upon the structure of part-time employment in one particular segment of the labour market. public hospital-based registered nursing. Nurses employed in general and obstetric public hospitals are represented by the New Zealand Nurses Association; nurses employed in psychiatric and psychopaedic hospitals are represented by the Public Service Association. The 2 organisations have adopted strikirigly different approaches to the issue of part-time employment.

The discussion that follows briefly summarises the evidence available on the patterns of part-time employment in registered nursing and the reasons for its growth. The responses made by the Nurses Association and the Public Service Association to the growth of part-time nursing are then outlined and compared, and an attempt is made to explain the differences in
approach.

\section{The growth of part-time nursing}

Part-time employment is today a prominent feature of the labour market in almost all areas of registered nursing employment. In 1984, 39 percent of all registered nurses employed in public hospitals, and 42 percent of those employed in general and obstetric public hospitals, were working part-time hours (New Zealand Department of Health. 1984, p. 18). ${ }^{1}$ Levels of parttime employment amongst district, Plunket and general practice nurses, and in private hospitals, were also high. ${ }^{2}$ In psychiatric and psychopaedic hospitals, however, and in public (14 percent, 8 percent and 6 percent of registered nurses were employed on a part-time basis Department of Health, 1984, pp. 18,33). Part-time is defined as less than 35 hours a week. District nursing services, tutors and students are
excluded from these figures.

2 Approximately 46 percent of district nurses, 54 percent of registered Plunket nurses, and 67 percent 33). The Department of Health has estimated 1984 (New Zealand Department of Health, 1984, p hospitals are employed part-time (King and Fletcher, 1981 percent of registered nurses in private 
Although little research has been undertaken to identify the causes of the growth of parttime nursing in New Zealand, the information available suggests that both post-war shortages of qualified nursing staff, and the benefits offered for staff scheduling flexibility, were of considerable importance in prompting nurse administrators to make greater use of part-time employment. Shortages of trained nurses in the years following the war, resulting both from the expansion of public health services and the trend towards earlier and more universal marriage encouraged hospitals to make greater use of qualified nurses who offered themselves on a part-time basis (Kendrick, 1950, p. 671; Pitts, 1984, p. 53). The Annual Reports of the Department of Health between 1946 and 1976 regularly referred to nursing shortages afflicting at least some areas of the country. Officials urged that hospitals make greater effort to recruit back into nursing married women who had left the profession and utilise married and part-time staff on afternoon and night shifts (Annual Reports 1969, p. 67; 1971, p. 79; 1972, p. 31; 1976, p. 83). Unfortunately, national data is not available to show the pattern of part-time job growth within the nursing workforce during the post-war decades. Anecdotal evidence suggests however that the proportion of part-time nurses in public hospitals probably remained relatively low throughout the $1950 \mathrm{~s}$ and early 1960s, but grew significantly in the late 1960s and 1970s.

Part-time employment has also been extensively utilised in both private and public hospitals to provide flexibility in the scheduling of nursing staff. An investigation of staffing patterns within public and private hospitals in Christchurch undertaken by the author in 1985 , provided many examples of the use of part-time staff for this purpose (see appendix). Adequate nursing coverage must be provided in hospitals on a 24-hour. 7-day-per-week basis, and a large amount of administrative time and effort is absorbed by the process of determining when each nurse will be on or off duty, which shift will be worked by whom and how weekends, absences and holidays will be accounted for (Young et al., 1981, p. 104). A common problem is the difficulty of staffing unpopular or socially inconvenient shifts: nights. Friday or Saturday evenings. public holidays. The use of compulsory full-time shift rotations to ensure adequate coverage at these times can cause major dissatisfactions among nursing staff. There are health and social problems associated with shiftwork, and it is also difficult to reconcile shiftwork with childcare responsibilities (Barnes, 1980, p. 27; Felton, 1975, p. 19). The creation of permanent part-time positions on the less popular shifts, such as nights, can assist hospitals to resolve this scheduling problem and provide 24-hour staff coverage without requiring nurses to rotate through a full 24-hour shift cycle (Godfrey, 1980, p. 67; J ohnson and Marcella, 1977; p. 34; Lartner, 1982, p. 168).

In each of the general and obstetric public hospitals studied in Christchurch in 1985, the majority of part-time nurses were employed permanently on the night shift, working 2, 3 and sometimes 4 nights a week on a regular basis. The growth of part-time employment in these hospitals over the past 5 to 10 years appears to have owed a good deal to the commitment of principal nurses to increasing the part-time coverage of the night shift, so as to reduce or eliminate the times when it was necessary to roster full-time staff nurses onto the night duty. Secondly, in every hospital for which information was obtained, permanent part-time nurses were utilised as relievers. As such they were requested to work extra duties when necessary on a voluntary basis to help cover for absences arising from sickness or annual leave. Nursing administrators generally preferred to call on their permanent part-time staff to cover these extra duties rather than to request full-timers to alter their rostered duty schedules at short notice or to work overtime. Thirdly, 2 of the larger public hospitals made use of nursing pools composed largely of part-timers. Pool nurses are not permanently assigned to a particular ward but instead are assigned to a place of work when they come on duty, according to need. Pool nurses functioned both to fill in gaps caused by sickness and to raise staff levels when necessary in areas of the hospital where fluctuations in workloads are particularly critical, such as the intensive care unit. Discussions with nurse administrators in the course of the research confirmed that they considered the scheduling flexibility provided by part-time employment to be one of its major advantages.

Neither the "staff shortage" nor the "scheduling" explanations for the growth of part-time registered nursing can explain the low level of part-time nursing found in psychiatric and psychopaedic hospitals. Historically, psychiatric and psychopaedic hospitals have experienced staffing problems at least as severe as those affecting general hospitals, and it is arguable that shortages of registered psychiatric nurses have been even greater. ${ }^{3}$ Nursing administrators

In 1972 a Royal Commission of Inquiry examined the justification for a salary lead for psychiatric nurses and recommended its retention specifically to encourage the recruitment and retention of nurses to the psychiatric field (New Zealand Royal Commission, 1972, p. 14). 
in psychiatric hospitals must also schedule staff on a 24-hour, 7-day basis and adjust to cover absences. To explain the different levels of part-time employment that exist in the general and the psychiatric spheres of registered nursing, it is necessary to take into account the impact of the professional associations upon staffing patterns.

\section{The responses of the Associations}

The expansion of part-time employment in public general and obstetric hospitals during the 1970 s occurred largely without any active response on the part of the Nurses Association. The Association has never developed a formal policy stance on the desirability of part-time employment in nursing, or the desirability of its expansion. While the importance of the trend towards part-time nursing has been acknowledged by Nurses Association leaders, they do not appear to have perceived this trend as an issue that required formal discussion and review at the executive level, either by the Association's executive or by any of its sub-committees.

Instead, the response of the Nurses Association to the expansion of part-time employment has been limited in its focus to a concern with ensuring that equality for part-timers in basic conditions of employment is maintained. The Association's executive officers adhere to the view that there should be no direct discrimination against part-time nurses with respect to nationally-regulated conditions. On several occasions during the 1970s, they acted on this belief by exerting pressure on the State Services Co-ordinating Committee (SSCC), through the then Combined State Service Organisations (CSSO), to ensure that certain newly-negotiated conditions of service for hospital employees were extended to part-time as well as full-time employees. In 1971, for example, a penal rate for hours worked at night was negotiated for the first time, but initially it was granted only to full-time nurses who rotated through the duty roster. The Association protested strongly and made a series of submissions to the Minister of Health and the SSCC, until the night rate was extended to part-time nurses and those on fixed shifts (Carey, 1984, p. 50). Between 1978 and 1981, the Nurses Association took action to ensure that extra leave for shiftworkers in the Hospital Service was extended to part-timers ("Shiftworker Part-Timers", 1981 , p. 33 and in 1980, to ensure that part-time nurses were paid transport allowances "NZNA Intervention", 1980, p. 25). In large part, however, conditions of employment for part-time nurses in public hospitals have improved without extensive pressure from the Association.

In contrast to the Nurses Association, the Public Service Association (PSA) adopted a very clear policy position on the desirability of part-time employment in psychiatric and psychopaedic hospitals. Following the appointment of significant numbers of part-time nurses in the early and mid-1970s, part-time employment became an issue of discussion by PSA sub-group committees located in individual hospitals. From about 1974 onwards, individual PSA subgroups began to develop policy positions on part-time employment, and to seek agreements with hospital administrators to regulate the numbers of part-time staff and the hours and duties they might work.

The issue of part-time employment was subsequently discussed at a national level by the Central Committee of the PSA's Hospitals Group. In 1978 the Hospitals Group considered and formally adopted a policy on part-time employment stating that:

The Association supports the policy of job-sharing, but rejects the use of part-timers as shiftworkers and rostered workers when used to the detriment of full-timers, and as cheap labour filling in gaps caused by unrealistic staffing levels and staff shortages.

The PSA's general position of opposition to an unrestricted expansion of part-time employment was implemented by PSA sub-groups around the country in various ways. While all sub-groups officially sought to contain part-time employment or regulate its growth, agreements reached with individual hospital boards and in particular hospitals, differed somewhat in their format and their restrictiveness. In addition, some sub-groups enforced the agreements more rigorously and consistently than others. One PSA official suggested that "when a subgroup is disciplined, firm and well-organised, they have been able to impose restrictions on part-time employment levels. Where not, it can be introduced".

At one major South Island hospital, for example, the PSA did not immediately oppose parttime employment when the growth began in the early 1970s. The number of part-time nurses grew slowly rather than suddenly, and hospital administrators did not advertise to recruit parttimers but rather appointed those individuals who offered themselves. In the later 1970s however, full-time staff members began raising part-time employment as an issue and 
bringing their grievances about part-time employment to PSA committee meetings. There was considerable discussion of the desirability and usefulness of part-timers, and a decision was reached within the committee that the growth in part-time numbers should be halted. An unwritten agreement that no more part-timers be appointed was then sought and obtained from the hospital's principal nurse. Existing part-time nurses retained their jobs, but their numbers were allowed to dwindle through natural attrition.

Agreements reached at other hospitals were usually more moderate. In general, agreements sought to limit the total number of part-time staff and to regulate the shifts and hours that parttimers may work, rather than to prohibit part-time appointments altogether. PSA groups in hospitals with particularly acute staff shortages found it more difficult to discourage part-time appointments entirely. Nevertheless, the agreements reached in most hospitals do seem to have been effective in containing the growth of part-time employment in the late 1970 s and early 1980s. Only one hospital had a "high" level of part-time employment among its nursing staff in 1980 and $1982^{4}$

The PSA's opposition to part-time employment in psychiatric hospitals has rested upon several objections. Firstly, PSA representatives have argued that the introduction of part-time workers with fixed hours into a working environment where the majority of the workforce are shiftworkers leads to serious and difficult problems of equity. Union representatives claim that the part-time nurses who were appointed in the 1970 s were frequently permitted to work the hours that suited them best: typically during evenings and on weekends. Part-time nurses doing weekend duties only were able to earn almost as much in two days as full-timers could earn working 4 weekdays. Moreover, the presence of the part-timers on these fixed duties also reduced the penal time earning opportunities of full-timers, since they were rostered onto weekend duties less often than would otherwise be the case. The PSA argues that for equity reasons part-timers should be used in such a manner that their presence does not have detrimental effects upon the working time patterns and earning opportunities of full-time staff.

Secondly, it is argued that because part-timers are so frequently absent from the workplace, their employment places extra burdens and demands upon full-timers. Part-timers are unable to carry their fair share of organisational and administrative responsibilities, such as the planning of therapy and activity programmes. Thirdly, it is said to be much more difficult to provide continuity of nursing care when part-timers are employed. On professional grounds, PSA officials argue that "patients should get to know their nurses". The growth of part-time employment would decrease the continuity of care.

Fourthly, PSA officials have argued that part-timers are much less interested in or concerned about employment conditions than are full-timers. They have little commitment to the union and tend to remain uninvolved in union activities. An expansion of part-time employment in psychiatric hospitals would therefore tend to undermine the PSA's organisational strength.

Finally, the PSA have argued that the growth of part-time employment could delay rather than advance the resolution of the staffing problems that have afflicted psychiatric hospitals. Since the 1940 s, the PSA has consistently maintained that staffing levels in psychiatric hospitals are inadequate to meet patient care needs. Actual staff numbers in psychiatric hospitals have frequently remained well below establishment levels, representing the total number of approved and funded positions, for long periods of time. Hospital boards have compensated for shortfalls in staff numbers by rostering staff onto "call back" (overtime) duties. During the 1970 s (according to PSA spokesmen) they continued to make much use of call back duties and pressed increasingly for the appointment of part-timers to provide peak period coverage. PSA officials have opposed this practice, arguing that part-timers should not be used to provide peak period coverage until such time as there are a sufficient number of full-time staff. Underlying the argument was a fear that hospital administrators might use part-timers as a convenient and relatively inexpensive "solution" to the staffing problem, a solution that would allow the full costs of raising staff numbers to establishment levels to be circumvented.

Braemer Hospital in Nelson, where 47 percent of registered nurses were employed part-time in 1982. Less than 14 percent of registered nurses in all other hospitals were part-time workers (New Zealand Department of Health, 1983, p.78).

5 Similarly, for equity reasons the PSA has maintained that all staff nurses should work the 4-day on, 2-day off duty roster that operates in psychiatric hospitals and take their turn at each of the daily shifts in rotation. 


\section{Explaining the policy divergence}

How do we account for the differences in the approaches of the Nurses Association and the PSA? Both organisations have adhered consistently to the view that part-time employees, if they are used at all, must be guaranteed the same rights and conditions that full-timers enjoy. Neither association has been prepared to accept discrimination against part-time nurses within the sphere of nationally-regulated conditions of employment. However, while Nurses Association leaders were prepared to embrace part-time employment as a solution to the shortage of registered nurses and as a means to improve the ratio of qualified to unqualified staff in the nursing service, the attitude of the Public Service Association has until recently been one of general opposition to the use of part-time nurses, except on a very restricted and conditional basis.

One possible explanation is that part-time nurses were in fact scheduled in different ways in psychiatric and general hospitals. In other words, ad hoc arrangements that suited administrators and part-timers but did not really take into account the wider impacts upon the working schedules of full-timers, may have been more commonplace in psychiatric than in general hospitals during the 1970s. Without historical data on institutional scheduling patterns. it is difficult to judge whether or not this was the case. However, it is very likely that the issues and problems posed by part-time employment were present in both psychiatric and general hospitals to some degree. ${ }^{6}$

The divergent approaches of the 2 organisations can be better explained in terms of differences in the goals and organisational structures of the 2 associations, and differences in the gender composition of their active memberships. The primary objectives and concerns of the Nurses Association have traditionally focused upon the promotion of professional standards in nursing services, the regulation and improvement of nursing education. and the economic welfare of the Association's members. These issues have been addressed at a national level and with a national perspective.

Moreover, the organisational structure of the Nurses Association, with its high degree of centralisation and its local branches organised on the basis of residence not place of work, is closer to that of an interest group than that of a trade union. It was not until the 1970s that the Association appointed its first full-time field officers to undertake the functions of industrial representation in the regions. Similarly, there was no organised Nurses Association presence in individual hospitals prior to the 1970s. In 1972 the Association made a commitment to establishing advisory and representation committees in each hospital, and recommended to the regional branches that they establish these committees. The development of the hospital committee structure was slow however (Carey, 1984, p. 35). Without an organised union presence in the workplace, staff nurses lacked channels through which they could express their views and grievances concerning hospital scheduling practices, or attempt to influence the
staffing decisions of nurse administrators.

The membership structure of the Nurses Association may also have helped to prevent it from acting as a channel through which the grievances of staff nurses regarding the impact of part-timers on workplace duty rosters could be expressed. The Association s membership includes nurses at all levels of responsibility in the profession, and there has been a tendency for senior nurses and nurse administrators to be over-represented within the Association's active membership, both in the branches and at the national level. The involvement of nurse view for or against part-time employment would emerge.

In contrast with the Nurses Association, the PSA has had a strong workplace presence in psychiatric and psychopaedic hospitals for several decades. Local PSA sub-groups have usually been well organised and active, and they have maintained a considerable interest and Advisory and Representatiostering decisions over the years. Unlike the Nurses Association active support of the membership in their PSA committees have been able to rely on the power to exert an influence over staffing and rostering with management, giving them greater structure through which staff stafing and rostering decisions. PSA sub-groups provided a nurses into psychiatric hosp introduction of part-time

Differences in the gender composition workforces may also have contributedion of the general hospital and psychiatric hospital 作 2 associa- 
tions, insofar as they shaped membership priorities and concerns. The nursing workforce in general hospitals is almost entirely female, while just under one-third of registered psychiatric nurses are men. Male nurses and psychiatric assistants have in the past tended to be more active within PSA sub-groups than female staff nurses. Income-maximising male nurses in psychiatric hospitals would have been particularly inclined to view part-time employment negatively, because of the threat it appeared to present to their earning opportunities. The implications of part-time employment for penal time earnings in situations where part-timers are concentrated on evening, night or weekend duties have been noted earlier. Part-time employment also had implications for overtime earnings, for if used to plug staffing gaps it would presumably have curtailed the number and frequency of call back duties. Thus the presence of a male minority in the psychiatric hospital workforce, and the disproportionate representation of male nurses on PSA committees, may have helped to shape the PSA's perception of the issues presented by part-time employment, making a negative response more likely.

In the mid-1980s, the PSA has come under new pressures from within its membership to reassess its position on part-time employment and move towards greater acceptance of parttime nursing on a conditional, negotiated basis. At the 1986 Hospitals Group Conference, a resolution was passed directing officials to enter into negotiations with the Health Services Personnel Commission, with a view to reaching agreement at a national level on the terms and conditions under which part-time employment might be introduced. The pressures for policy change stem primarily from the demands increasingly expressed by members in recent years for improved part-time working opportunities. A gradual increase in the active involvement of women at all levels of the Hospitals Group during the early 1980 s may have assisted advocates of part-time employment to gain greater voice within the union. In response to the shift of emphasis in membership claims. PSA officials have acknowledged that there is a need to provide employment opportunities for trained nurses who cannot continue full-time nursing because of their childcare responsibilities, and maintain that they support the concept of permanent part-time employment as a way to satisfy this need. provided certain conditions are met.

At the time of writing. details of a part-time work claim to be placed before the Health Services Personnel Commission later in 1986 were still being formulated within the PSA. Officials made it clear, however, that the agreement they sought would involve an explicit regulation of the total number or proportion of part-time positions in each hospital, and would place limits on the hours and shifts that part-time nurses might work. A high priority would be placed on preserving intact the 4-day on. 2-day off roster presently worked by the psychiatric nursing workforce, and on minimising the impact of part-timers on the duty schedules of fulltimers. The PSA is not prepared to grant employers an open licence to employ part-timers on terms of their own choosing. As one union representative explained, "our main concern is that it comes in on our terms, and by agreement"

\section{Conclusions}

It has been suggested that the labour market can be viewed as an arena of bargaining relationships. Labour market outcomes emerge out of the efforts of firms and workers to shape the characteristics of jobs to the forms most advantageous to each(Finlay, 1983, p. 306). The role played by trade union organisation in structuring and segmenting the labour market has been commented on in recent years by a number of theorists writing from the perspective of segmentated labour market theory (for example. Craig et al., 1985; Kahn, 1975; Rubery, 1978). Sociologists have also drawn attention to the role of trade union activity in the creation and maintenance of gender segregation in the workforce (for example, Cockburn, 1983). In this paper I have argued that the number and availability of part-time jobs is a further dimension of labour market structure that can be shaped by bargaining between unions and employers or by bargaining within occupational groups.

The Public Service Association's opposition to the unrestricted growth of part-time employment in psychiatric hospitals was based on a perceived conflict between the earning opportunities and working time preferences of full-time and part-time members. The introduction of part-time staff into a shiftworking environment, where occupational group members typically wish to attain some control over the pattern of their working hours raised issues of choice and equity. The conflict was resolved in the $1970 \mathrm{~s}$ in favour of full-time members by preserving the existing rostering arrangements intact and limiting the number of part-time 
jobs. The level of part-time employment aimed at by PSA sub-groups was the lowest level pragmatically possible without jeopardising the employment contracts of existing part-time staff. It was not determined by any assessment of what particular mix of full-time and part-time positions would best correspond to the needs and preferences of the workforce as a whole. It could be argued that this particular resolution of the issue can only have limited the employment options open to Association members, especially those with childcare responsibilities, and made it more difficult for them to retain their involvement in the nursing profession during their child rearing years.

The case of registered nursing suggests that trade union or occupational group opposition to part-time employment is particularly likely to arise in workplaces where shiftworking premia, penal-time rates or overtime payments make an important contribution to regular weekly earnings, since part-time employment threatens to undermine the established systems of work organisation on which these supplementary earnings are based. While the hospitals sector is obviously one such sector of the workforce, the transport, communications and distribution industries are examples of other sectors where one would expect such conflict to
occur.

The case study also offers insight into the circumstances that make it possible for unions or professional associations to regulate part-time employment in an effective manner. The PSA's ability to regulate in psychiatric hospitals depended upon the prior existence of both collective organisation and effective negotiating channels in the workplace that could be used for the purpose of bargaining over staffing decisions. The limited development of trade union organisation at this level in general and obstetric hospitals at least partly explains why a regulation of part-time employment did not occur in that sector. It is worth noting that the workplace-based 作 among skilled occupational groups, even if it is less common in occupations with a majority of
female members than in those with a majority of males.

More broadly, the example of registered nursing suggests that the internal decision-making institutions of unions and professional associations in many sectors of the workforce may part-time workers, whay as to make them relatively unresponsive to the needs and preferences of following efforts within participation, and following membership part-time employment, has the PSA fully pressure for a reassessment of union objections to working opportunities and the legitimacy of claims for part-time employment and the apparent conflict between part-time responsive to minority interests within priority to the needs of part-time me low opportunities.

\section{Appendix}

The case study presented in this paper is based upon research undertaken by the author in 1985, as part of her MA Thesis. Interviews with nurse administrators and part-time nurses employed in 11 public and private Christchurch hospitals, interviews with professional association representatives, and documentary sources such as professional journals, provided the in the 11 hospitals studied, and inform the hours and duty schedules worked by part-time nurses obtained through the interviews with part-tim on hospital staffing and scheduling policies, was on the policies of the Nurses Association and nurse administrators. Information Nurses Association and PSA representatives, account of the research methods, see Dixon (1985,

\section{References}

Aiken, L (1984) The nurse labor market Journal of nursing administration 14(1): 18-23. Barnes, H (1980) Night work for nurses New Zealand nursing journal 73(5): 22-29.

Beechey, V and Perkins, T (1985) Conceptualising part-time work. In Roberts, B et al.(Eds) New
approaches to economic life: economic restructuring and the social division of labour $\mathrm{Man}$ chester, Manchester University Press. 
Bennett, B (1962) Part-time nursing employment in Great Britain, International labour review 85(4): $347-56$.

Bosworth. D and Dawkins, P (1982) Women and part-time work Industrial relations journal 13(3): $32-39$.

Canadian Commission of Inquiry into Part-time Work (1983) Part-time work in Canada Ottawa. Labour Canada.

Carey, S (1984) Professionalism and unionism: transcending the conflict. In Gibson Smith, M and Shadbolt. Y (Eds) Objects and outcomes: New Zealand Nurses Association 1909-83 Wellington. New Zealand Nurses Association.

Clark. A (1986) Part-time work in New Zealand Wellington. New Zealand Planning Council.

Cockburn, C (1983) Brothers: male dominance and technological change London, Pluto Press.

Craig, C, Rubery, J, Tarling, R and Wilkinson. F (1985) Economic, social and political factors in the operation of the labour market. In Roberts. B et al. (Eds) New approaches to economic life: economic restructuring and the social division of labour Manchester, Manchester University Press.

Dixon, S (1985) The growth of part-time employment: cause or solution to sex inequalities in the labour market MA Thesis, University of Canterbury.

Felton, G (1975) Body rhythm effects on rotating work shifts Journal of nursing administration 5(3): 16-19.

Finlay, W (1983) One occupation, two labor markets: the case of longshore crane operators American sociological review 48(3): 306-15.

Godfrey, M (1980) The part-time question and the hospital's answers Nursing ' 80 November. $66-72$.

Hall, T and Hall, P (1980) Part-time social work London, Heinemann.

Hallaire, J (1968) Part-time employment: its extent and its problems Paris, OECD.

Humphries, J (1983) Part-time work London, Kogan Page.

Johnson. P and Marcella, M (1977) Part-time nursing employment: worry or worth? Supervisory nurse $\mathbf{8}(1)$ : 34-36.

Kahn, L (1976) Internal labor markets: San Francisco longshoremen Industrial relations 15(3): 33-37.

Kelsall, K (1980) Teaching. In Silverstone, R and Ward, A (Eds) Careers of professional women London, Croom Helm.

Kendrick, S (1950) The shortage of nursing staff: a suggestion to improve the situation New Zealand medical journal 49(274): 671-75.

King, B and Fletcher, P (1981) The nursing workforce in New Zealand, 1980 Blue Book Series No 10. Wellington, Management Services and Research Unit, Department of Health.

Lartner, M (1982) Creative staffing. In Marriner, A (Ed) Contemporary nursing management: issues and practice St. Louis, C V Mosby.

MacGuire, J (1980) Nursing. In Silverstone, R and Ward, A (Eds) Careers of professional women London, Croom Helm.

New Zealand Department of Health (1983) The nursing workforce in New Zealand, 1982 Blue Book Series No 17. Wellington, Division of Nursing, Department of Health.

New Zealand Department of Health (1984) The nursing workforce in New Zealand, 1984 Blue Book Series No 22. Wellington, Division of Nursing, Department of Health.

New Zealand Department of Health Annual reports 1969, 1971, 1972, 1976 Wellington.

New Zealand Royal Commission of Inquiry into Hospitals and Related Services (1972) Differential pay scales for psychiatric and psychopaedic nurses Wellington, Government Printer. 
Nollen, S, Eddy, B and Martin, V (1978) Permanent part-time employment: the manager's perspective New York, Praeger.

NZNA Intervention gets transport allowance reinstated for part-timers (1980, March) New Zealand nursing journal 73(3): 25.

OECD (1983) OECD employment outlook, September 1983 Paris, OECD.

Pitts, A (1984) Nursing services. In Gibson Smith, M and Shadbolt, Y (Eds) Objects and outcomes: New Zealand Nurses Association 1909-83 Wellington, New Zealand Nurses Association.

Quarterly Employment Survey, October 1947 and February 1986. Wellington, Department of Labour.

Robinson, O (1979) Part-time employment in the European community International labour review 118(3): 299-314.

Robinson, O and Wallace, J (1984) Part-time employment and sex discrimination legislation in Great Britain Research Paper No 43, London. Department of Employment.

Rubery, J (1978) Structured labour markets, worker organisation and low pay Cambridge journal of economics 1978(2): 17-36.

Shiftworker part-timers and extra leave (1981, June) New Zealand nursing journal 74(6): 33.

Shipley, S (1982) Women's employment and unemployment: a research report Palmerston North. Massey University and SROW.

Syrett, M (1983) Employing job sharers, part-time and temporary staff London. Institute of Personnel Management.

Thomas, B and Deaton. D (1977) Labour shortage and economic analysis: a study of occupational labour markets Oxford. Basil Blackwell.

Use of auxiliary and lay help in the nursing services (1959. April) New Zealand nursing journal 52(2): 39-40.

White. J (1982) Women and part-time work Ottawa. The Canadian Advisory Council on the Status of Women.

Young. J. Giovannetti. P. Lewison. D and Thoms, M (1981) Factors affecting nurse staffing in acute care hospitals: a review and critique of the literature Hyattsville. Maryland. United States Department of Health and Human Services. 